\title{
1 Urbanization and the Thermal Environment of Chinese and US-American Cities
}

2 Danlu Cai ${ }^{\mathrm{a}}$, Klaus Fraedrich ${ }^{\mathrm{b}}$, Yanning Guan ${ }^{\mathrm{a}}$, Shan Guo ${ }^{\mathrm{a}}$, Chunyan Zhang ${ }^{\mathrm{a}}$

3

$4{ }^{a}$ Institute of Remote Sensing and Digital Earth, Chinese Academy of Sciences, Beijing,

5

China

6

${ }^{b}$ Max-Planck-Institute for Meteorology, Hamburg, Germany

7

8 Corresponding author: guanyn@ radi.ac.cn (Yanning Guan); caidl@radi.ac.cn (Danlu 9 Cai) 
10 Abstract: Urbanization induced change of the thermal environment of cities is

11 analyzed using MODIS LST and DMSP/OLS nighttime light data sets (2001-2012) to a) extend previous studies on individual megacities to a city size spectrum; b)

13 investigate the heterogeneous surface thermal environment associated with the

14 urbanization processes in terms of nighttime light intensity and city size; and c)

15 provide insights in predicting how urban ecosystems will respond to urbanization for

16 both a developing and a developed country (China and US-America), and on global

17 scale. The following results are obtained: i) Nighttime light intensities of both

18 countries (and globally) increase with increasing city size. ii) City size dependent

19 annual or seasonal mean temperature tendencies show the urban effect by decreasing

20 daytime and increasing nighttime mean temperatures (particularly in China) while

21 variability can be related to climate fluctuations. iii) Daytime/nighttime seasonal

22 warming tendencies (inferred from regional downscaling within city clusters) show

23 the high light intensity regions to be stable while in low light intensity regions

24 fluctuations prevail.

25 Keyword: Surface Thermal Environment, Urbanization, Light Intensity, City Size, 
26 MODIS Daytime/Nighttime Temperature Tendency 
28 The global urbanization process, where human population, material demands of

29 production, human consumption and urban waste discharge expand and become more

30 intense, has recently emerged as a sustainability challenge in an increasingly

31 urbanized world (Alberti 2005; Johnson 2001; Montgomery 2008; Pataki et al. 2006;

32 Ren 2015). Whereas in 1900 a mere $10 \%$ of the global population were urban

33 dwellers, that percentage now exceeds $50 \%$ and will rise even more to approach the

$3480 \%$ urbanization level of most industrialized nations today (Grimm et al. 2008). That

35 is, global urban population is projected to increase by 2.7 billion in 2050, nearly

36 doubling today's urban population of 3.4 billion (UN 2010). In addition, urban surface

37 climate is generally characterized by higher surface air temperature, weaker mean

38 wind speed, and lower relative humidity compared with its surrounding suburbs and

39 countryside (Landsberg 1981; Oke 1987).

40 Although global and regional climate changes are known to have an impact on

41 altering the urban surface climate, the urbanization/anthropogenic induced change in

42 surface parameters, including increased atmospheric greenhouse gas concentration, 
44 formation and evolution of urban climates (Grimm et al. 2008; Ren 2015; Wu and

45 Yang 2013). Kalnay and Cai (2003) estimated urbanization and other land-use

46 changes accounting for half of the observed reduction in the diurnal temperature

47 range and an increase in mean air temperatures in the United States during the past

48 century. The best-documented example of anthropogenic climate modification is the

49 urban heat island effect (Landsberg 1981; Oke 1987), which affects not only local and

50 regional climate, but also water resources, air quality, human health, and biodiversity

51 and ecosystem functioning (Platt et al. 1994). Thus, research on the effects of

52 global/regional urbanization on urban surface thermal environment may provide

53 insights in predicting how urban ecosystems will respond to urban climate change

54 (Carreiro and Tripler 2005).

55 Research on global/regional urbanization requires the definition of urban land use,

56 which can be different depending on the questions being addressed (Schneider and

57 Woodcock 2008, see also http://blogs.worldbank.org/sustainablecities/what-

58 does-urban-mean): i) socio-demographic definitions involve administrative 
59 boundaries, population size or density, and economic indicators (Utzinger and Keiser

60 2006); and ii) physical definitions use the presence of human-made structures and

61 materials (Mertes et al. 2015; Taubenböck et al. 2014). Unlike traditional

62 socio-demographic research, employing remote sensing techniques to analyze

63 physical human-made structures and materials in urban surface environment is a

64 relatively recent field of research (Small et al. 2011), and has potential to obtain more

65 comprehensive characteristics relating to urban dynamics and associated

66 environmental consequences during the urbanization processes (Ma et al. 2012).

67 Nighttime light signals derived from the Defense Meteorological Satellite Program's

68 Operational Linescan System (DMSP/OLS) provide striking remotely sensed data to

69 analyze spatiotemporal changes in global urbanization processes (Elvidge et al. 1997;

70 Small and Elvidge 2011; Small et al. 2005; Sutton 2003). Most previous studies have

71 attempted to quantify the correlation between night lighting areas and urbanization

72 variables, including urban expansion (Huang et al. 2016; Zhang et al. 2015),

73 population growth (Ghosh et al. 2010; Sutton et al. 2001; Zhang and Seto 2011), gross

74 domestic product (Doll et al. 2006; Henderson et al. 2012; Sutton and Costanza 2002), 
and electric power consumption (Amaral et al. 2005). However, to our knowledge,

76 few studies have been concerned with the quantitative relationship among global,

77 regional DMSP/OLS nighttime light signals and remote sensing based

78 urbanization-related surface thermal changes, particularly on a basis of a city size

79 spectrum analysis (details see section 2).

80 Unlike using station and simulation data covering socio-demographic areas, remote

81 sensing based technique of physical human-made nighttime light area is used in this

82 study to define urbanization based land use (or city size) and thus to analyze the

83 interrelationship, change tendency and variability of city size, light intensity and

84 urban surface air temperature. It will help enhance our understanding of the

85 spatiotemporal characteristics of urbanization and urban surface thermal environment

86 in global and regional scale. After introducing the remote sensing-based DMSP/OLS

87 nighttime light signals and surface air temperature datasets, methods of analysis are

88 presented (section 2). Global, countrywide and regional comparison of urban thermal

89 environment and its relation to city size and nighttime light intensity is discussed

90 (section 3), followed by a concluding summary (section 4). 


\section{2. Data and Methods of Analysis}

92 Small et al. (2011) indicate that the idea of defining a city as a discrete entity with

93 fixed administrative boundaries may be fundamentally flawed, because human

94 settlement patterns and, more generally, land surface modification can be represented

95 as continuous spatial variation in intensity of development or degree of modification.

96 In this study, spatiotemporal changes of urbanization obtained from global

97 DMSP/OLS nighttime stable lights products (1992, 2002 and 2012, acquired from

98 NOAA National Geophysical Data Center) with the brightness range $D N$ of 0 to 63 at

99 the spatial resolution of 30 arc-seconds $(\sim 1 \mathrm{~km})$ are used. To reduce the effects of

100 over-glow, usually caused by anthropogenic activities in undeveloped areas that were

101 not taken into account in statistical data of urban development (Elvidge et al. 1997;

102 Small et al. 2005), only spatially contiguous lighted pixel units (subscript 'i') with

$103 D N_{i} \geq 12$ are discussed below as cities (detailed descriptions of data quality control

104 and threshold choosing see Small et al. (2011)). The area of each pixel within

105 spatially contiguous lighted areas, $a(j)$, is defined as $a_{i}$. Thus a city (numbered by ' $\mathrm{j}$ ')

106 is characterized by its size, size(j). Its light intensity and its light variability are 
107 deduced from the spatially contiguous lighted area with brightness $D N_{i} \geq 12$. Thus, $j$

108 corresponds to the sequence of spatially contiguous areas exceeding the brightness

109 threshold and $i$ corresponds to the number of pixels in each of these areas. That is

$110 \quad \operatorname{City} \operatorname{size}(j)=\sum_{i} a_{i}(j)$

111 Light intensity $(j)=\left(\sum_{i} D N_{i}\right) / \operatorname{size}(j)$ and

Light variability $(j)=\operatorname{std}\left(D N_{i}\right)$

112 The city size spectrum analysis provided in this study is inspired by the power-law or

113 Zipf's law which implies that small occurrences are extremely common, whereas

114 large instances are extremely rare (Adamic 2000). That holds for huge city samples in

115 a global and subcontinental scale analyses, and it will circumvent limitations of

116 previous studies with their inconsistencies, including differences of time period,

117 regional span and analysis method (see subsections 3.1 to 3.3).

118 Twelve years of land surface temperature (LST) data of Moderate Resolution Imaging

119 Spectroradiometer (MODIS, MOD11C3) is analyzed provided monthly at $0.05^{\circ}$

120 spatial resolution as a gridded level-3 product for daytime and nighttime to calculate 
121 temperature tendencies from 2001 to 2012. To be comparable, the DMSP/OLS

122 nighttime stable light products are resampled according to the spatial resolution of

123 MODIS LST data. Intra-annual seasonality and annual mean temperatures are

124 calculated before a simple linear regression model (against year) is used to obtain the

125 temperature change trend/slope. Inter-annual temperature change tendencies of spring

126 (March to May), summer (June to August), autumn (September to November), winter

127 (December to February) and annual mean of the surface air temperature are evaluated

128 by $F$-test with all significance levels at the $P$-value $<0.05$ level (unless noted

129 otherwise).

130 Scale dependent analysis (section 3) includes a city unit (city size spectrum analysis,

131 see subsection 3.1-3.3) and a pixel unit (see subsection 3.4). Amongst, brightness $D N$,

132 daytime and nighttime temperatures and their related tendencies are recorded as pixel

133 units. City size, light intensity, light variability and related city size based averaged

134 temperature tendencies for both daytime and nighttime are calculated in terms of city

135 units. Therefore, besides urbanization and heterogeneous surface thermal environment

136 on individual megacities (subsection 3.4), this study extends the analyses to a city size 

spectrum both for China and America and on global scale, which to our knowledge, is 138 new. 
140 The geographical setting in Figure 1 displays the space, landscape and intensity

141 change of nighttime lighted area and their related variations of urbanization process: i)

142 Accurate information related to the spatiotemporal extent and dynamics of urban

143 surface energy fluxes is especially necessary for China (see Figure 1a-b) which, in the

144 past decades, experienced rapid urban development (Frolking et al. 2013). In the two

145 decades (1992-2012), the land used for urban construction in China has expanded in

146 all directions from the original core function zone (highlighted in Figure 1c-e, detailed

147 statistics see table 1), while no obvious urban area expanding pattern in the main city

148 zone of America could be found. ii) There is a green patch (2012) that looks like a big

149 city near Williston, North Dakota, America, although there is mostly grass and no big

150 city in that part of North Dakota. In fact, those lights could not be detected six years

151 ago before the oil boom based on fracking technology started (details see Krulwich

152 (2013)). Note that there is also another large light trend of shale gas production in

153 south Texas and a very large area of non-urban light in China on the loess plateau

154 north of Xi'an (pers. communication by reviewer). iii) Possible distinctions between 
155 China and US-America with respect to urbanization may provide insight for

156 understanding of urban climates in countries undergoing a more stable compared to a

157 rapidly changing development. City clusters of Beijing-Tianjin, Pearl River Delta,

158 Yangtze River Delta, New York, Los Angeles and San Francisco and their related

159 spatial averaged summer surface temperature time series are displayed geographically

160 and statistically (Figure 2), showing a decreasing (increasing) warming tendency in

161 daytime Beijing-Tianjin, Pearl River Delta and San Francisco (others) city clusters,

162 and a increasing warming tendency in nighttime city cluster, except for San Francisco

163 with slope $\sim-0.01$. For detailed spatial temperature changes see section 3.4. 


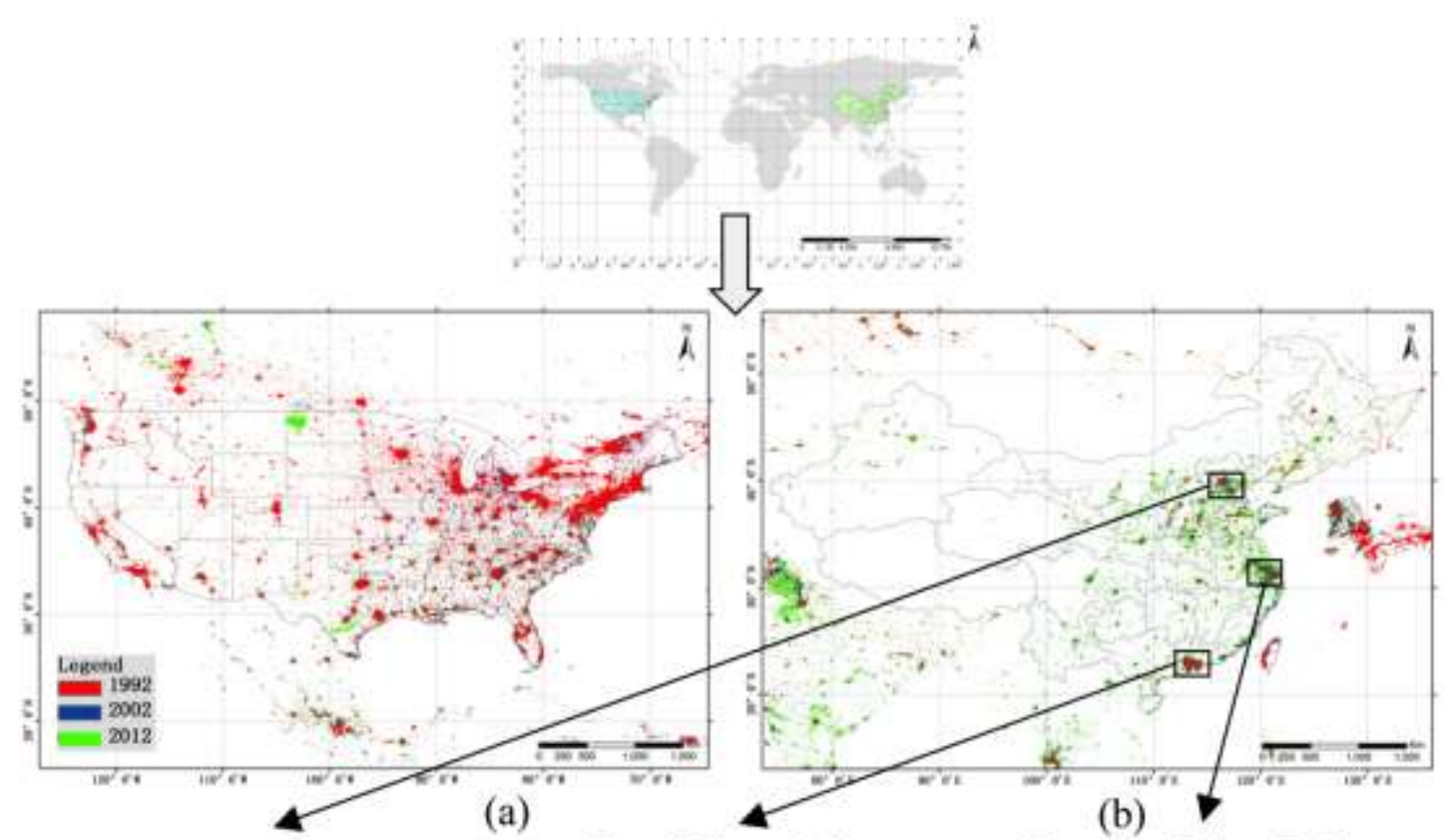

Beijing-Tianjin region

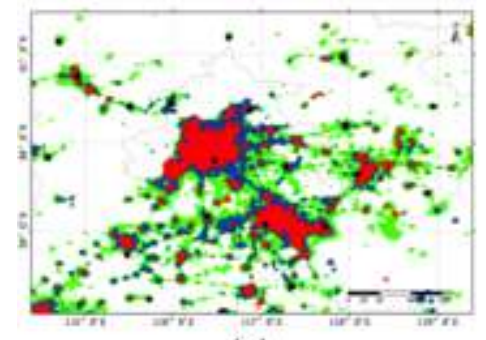

(c)

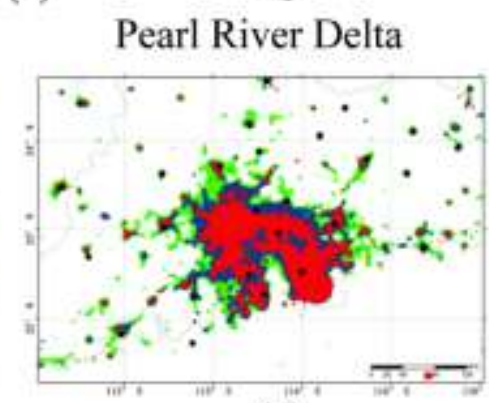

(d)
Yangtze River Delta

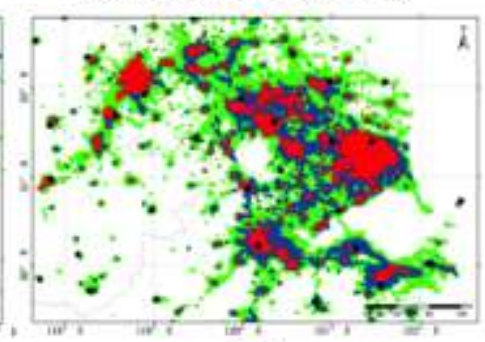

(e)

165 Figure 1 Geographical setting of spatiotemporal city size changes of 1992 (red), 2002 (blue) and 2012 (green) using DSMP/OLS nighttime light data for a) America, b)

China, and for three major city clusters in China of c) Beijing-Tianjin region; d) Pearl River Delta; and e) Yangtze River Delta. Spatially contiguous lighted areas with $D N \geq$ 12 are classified as cities (detailed descriptions of data quality control and threshold selection see Small et al. (2011)).

Table 1 City size comparison for three major city clusters in China: spatially contiguous lighted areas in 2012 (with DSMP/OLS $D N \geq 12$ are classified as city boundaries).

\begin{tabular}{cccc}
\hline Pixel number $(>\mathbf{1 2})$ & $\mathbf{1 9 9 2}$ & $\mathbf{2 0 0 2}$ & $\mathbf{2 0 1 2}$ \\
\hline Beijing-Tianjin Region & 13,719 & 22,327 & 44,023 \\
Pearl River Delta & 16,167 & 21,593 & 31,795 \\
Yangtze River Delta & 18,881 & 38,512 & 78,286 \\
\hline
\end{tabular}



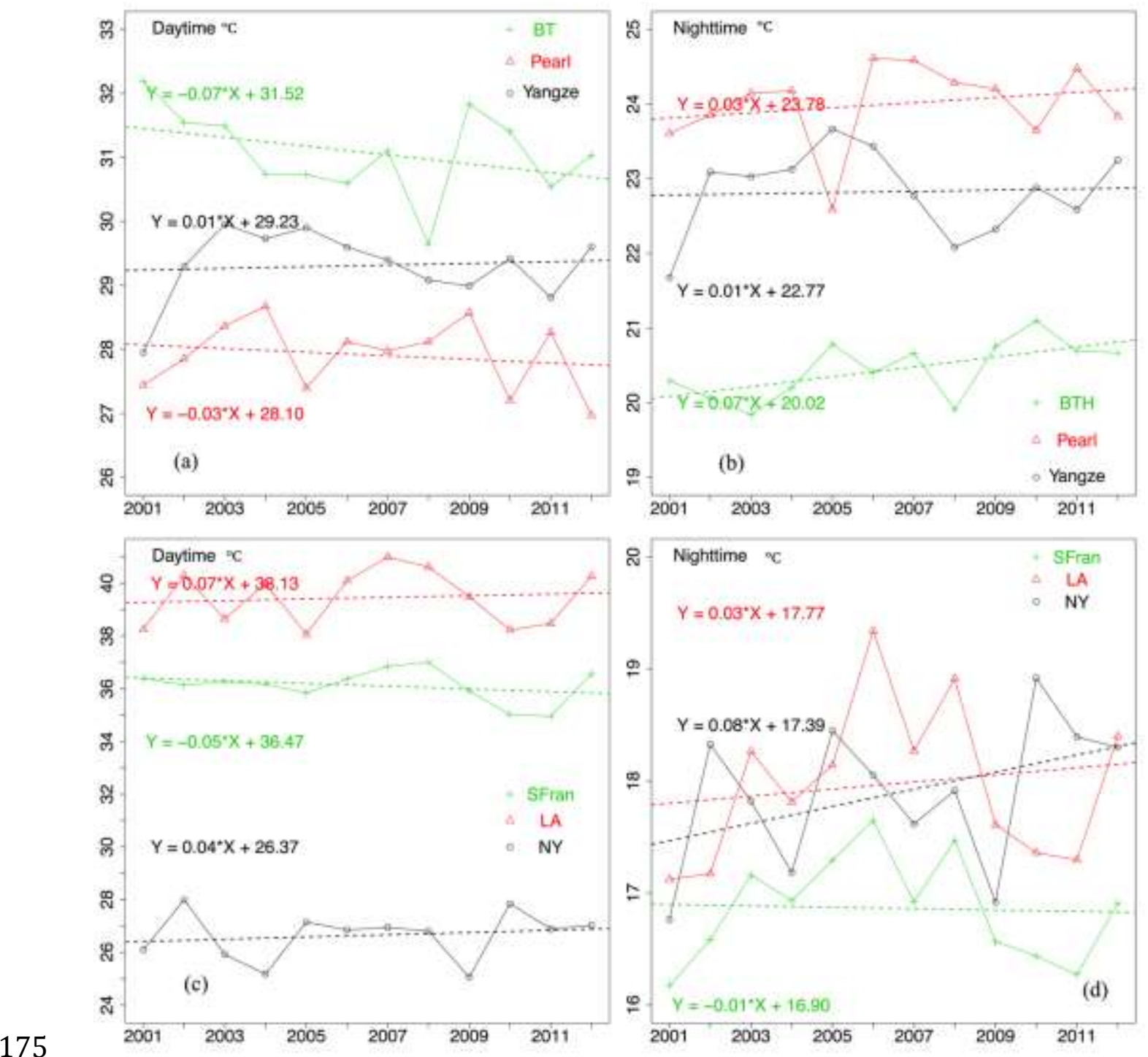

Figure 2 Time series comparison of several American and Chinese city clusters of surface temperature for day- and night-time (a-b) Beijing-Tianjin (BT), Pearl River

\subsection{City Size and Light Intensity}


184 light intensity (accumulated brightness per area, see section 2) and spatially averaged

185 temperature tendencies (discussed in subsections below). Figure 3 demonstrates the

186 relationship between city size and light intensity on global scale, and for China and

187 America: i) Like a power-law or Zipf's law implies that small occurrences are

188 extremely common, whereas large instances are extremely rare (Adamic 2000), small

189 size cities prevail in terms of number compared with megacities, and thus statistics

190 interval of city size is binned into exponentially wider bins with a base of $2 \mathrm{~km}^{2}$ to get

191 a suitable display. ii) No obvious distinction could be found in statistics of the (city

192 size, light intensity/variability)-diagram analyzing the global and the sub-continental

193 scale of China and America. iii) Light intensity and variability increase with

194 increasing city size subject, however, to small fluctuations. That is, high light

195 intensity > 40 exists in cities (city clusters) ranging from 16,384 to $32,768 \mathrm{~km}^{2}$. For

196 huge cities/city clusters $>\sim 32,768 \mathrm{~km}^{2}$, light intensity is averaged/decreased to $\sim 30$.

197 Here the variability is measured in terms of standard deviations and coefficients of

198 variation (ratio of regional standard deviation to regional mean) binned in area

199 classes. 

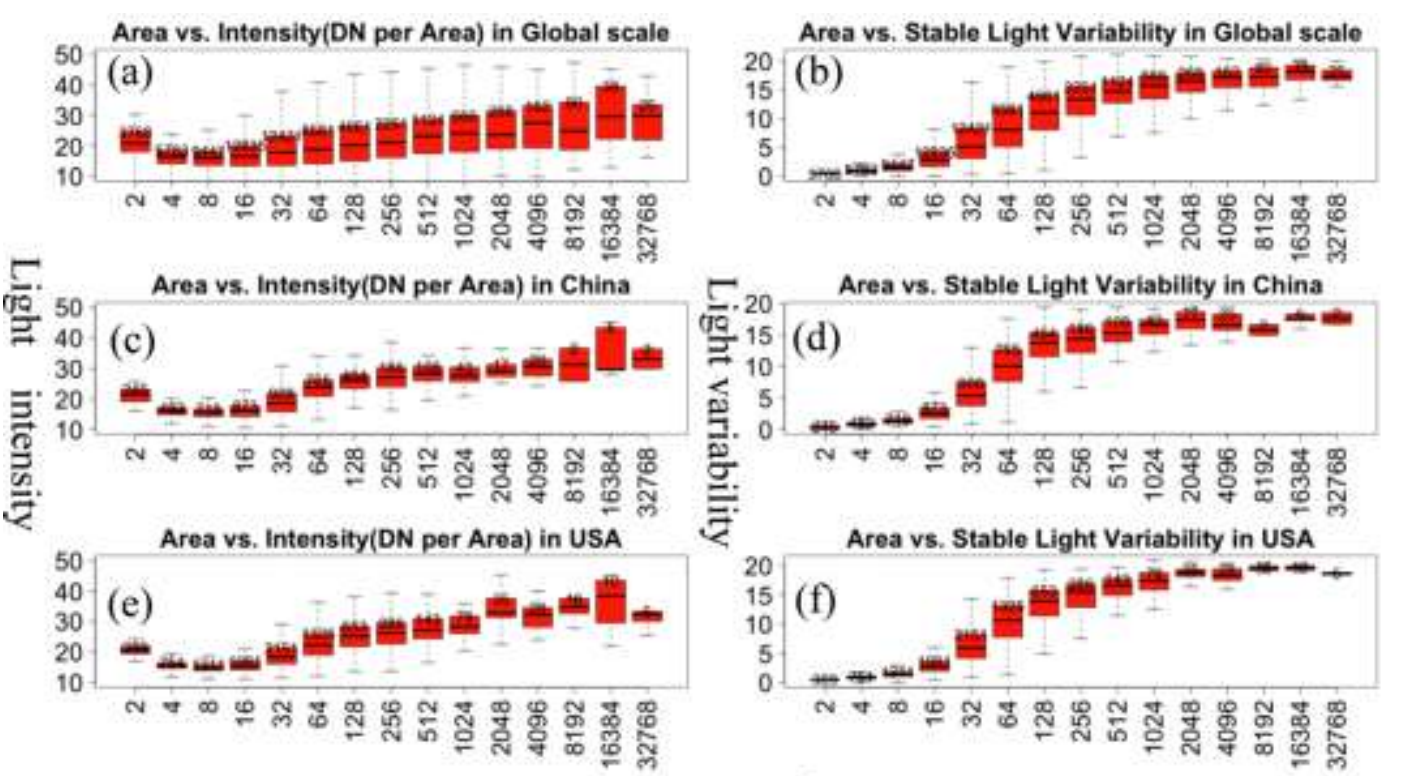

\section{City size $\left(\mathrm{km}^{2}\right)$}

Figure 3 City size dependent analyses of nighttime light a) intensity (accumulated brightness per city) and b) variability (standard deviation of nighttime light intensity of the global); c) intensity and d) variability in China; and e) intensity and f) variability in America. City sizes are binned into exponentially wider bins to circumvent the situation that few numbers of cities appear in large city size ranges

\subsection{City Size and Temperature Change} The Urban Heat Island effect suggests that land surface is replaced by anthropogenic material overlays, which lead to changes in urban thermal characteristics, especially

210 in megacities. The possible distinct influences of urbanization on the urban warming

211 effect are analyzed comparing a near stable (America) and a more rapidly changing

212 developing country (China). First we observe that, from 1992 to 2012 (see Figure 1)

213 the urban constructions in China have expanded in all directions but no obvious 
215 between city sizes extracted from 2012 nighttime light data and their related MODIS

216 LST tendencies (2001-2012) on both global and on country scale, the following

217 results are noted (Figure 4):

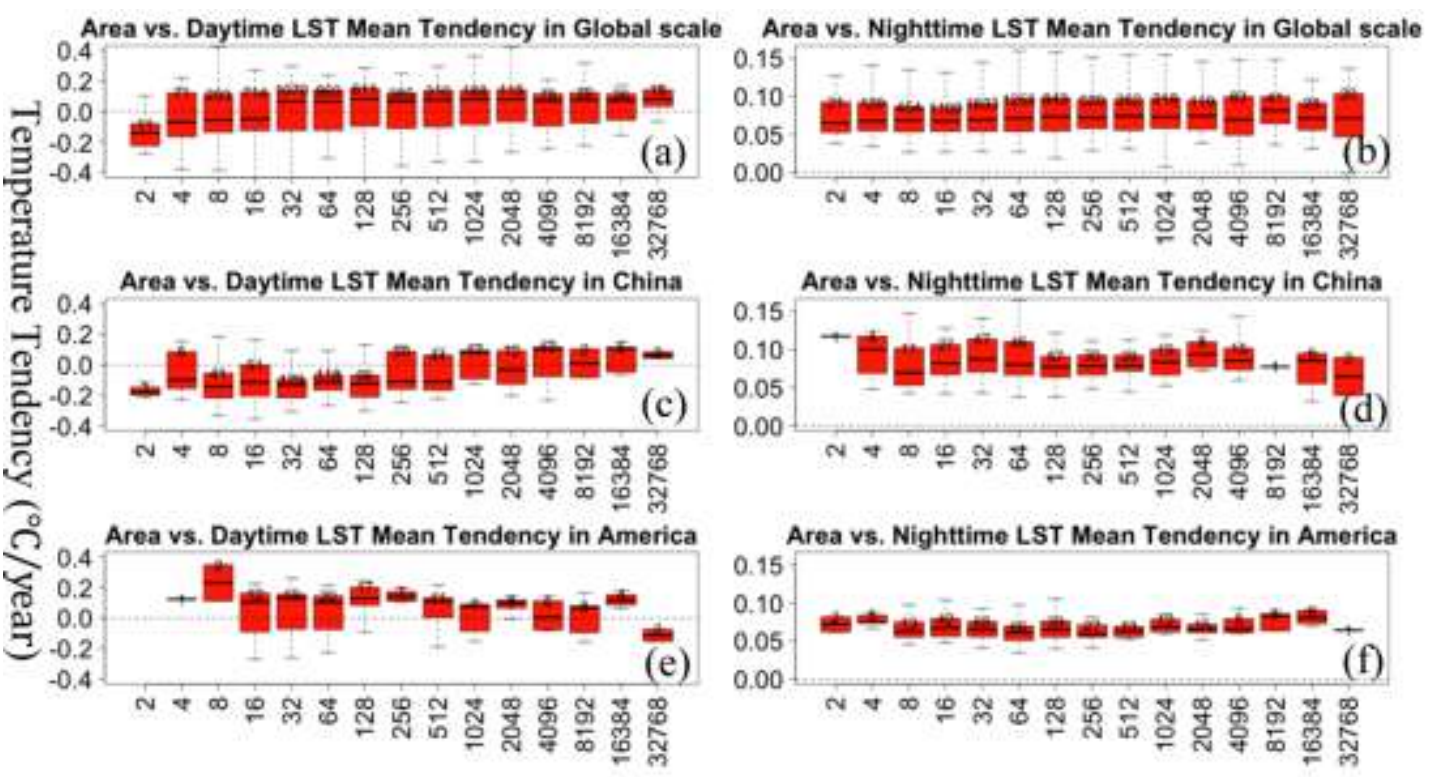

City size $\left(\mathrm{km}^{2}\right)$

219 Figure 4 City size dependent analyses of MODIS daytime and nighttime annual 220 averaged land surface temperature tendencies (2001-2012): a-b) on global scale, c-d) 221 in China, and e-f) in America. City sizes are binned into exponentially wider bins to circumvent the situation that few numbers of cities appear in large city size ranges (city size unit: $\mathrm{km}^{2}$, tendency (2001-2012) unit: ${ }^{\circ} \mathrm{C} /$ year).

224 i) For MODIS daytime annual mean tendency, globally (in China and in US-America), $56.63 \%(24.79 \%$ and $72.22 \%)$ cities are undergoing statistically significant warming in the daytime annual mean tendency. While for nighttime annual mean tendency, a 

hundred percent of the whole city size is found showing a warming tendency. That is,

228 cities are more likely to show urban warming rates with temperature decreasing in the

229 daytime and an increasing in the nighttime which is comparable with previous results 230 that urbanization may weaken (strengthen) urban warming rates in the daytime 231 (nighttime) as shown by Kalnay and Cai (2003) and Ren (2015).

232 ii) For MODIS daytime annual mean tendency, the increasing rates of mean (averaged 233 median) are $0.30(0.33),-1.02(-0.53)$ and $0.80(0.94){ }^{\circ} \mathrm{C} / \mathrm{decade}$ for global scale, 234 China and America, respectively. And for nighttime annual mean tendency, the 235 increasing rates in terms of mean (averaged median) are $1.02(0.71), 0.37(0.84)$ and $0.47(0.67){ }^{\circ} \mathrm{C} / \mathrm{dec} a d e$ for global scale, China and America, respectively. The most 237 obvious difference between mean and median, daytime and nighttime temperatures 238 occurs in China which may be related to the fact that the large and significant 239 urbanization-induced warming has contributed to changes in climate change induced 240 extreme temperatures in China (Ren and Zhou 2014; Zhou and Ren 2012).

241 iii) Previous studies (focusing on megacities) are extended to a city size spectrum.

242 Comparing annual averaged daytime temperature trends on global scale, China and 
243 America shows differences between small to moderate size and mega- cities. On

244 global scale (China), city size less than $\sim 30 \mathrm{~km}^{2}\left(\sim 200 \mathrm{~km}^{2}\right)$ mainly shows a cooling

245 tendency in daytime temperature, while most of the cities in America show a warming

246 tendency independent from city size. However, no obvious difference between small

247 and mega cities could be found in annual averaged nighttime temperature tendency.

248 Mackey et al. (2012) demonstrate that albedo increases produced greater cooling than

249 the NDVI increases. Observation of aerial images confirmed that typical instances of

250 efforts to increase albedo, such as reflective roofs, produced stronger cooling than

251 common instances of efforts to change NDVI, such as greening roofs, planting street

252 trees and providing green spaces (Mackey et al. 2012). In China, small to moderate

253 size cities experienced rapid urban development in terms of land cover type changes

254 (attribution changes): vegetated land surface is replaced by anthropogenic material

255 overlays; in megacities, however, land cover type has remained unchanged and kept

256 its attribution in the reconstruction process. In US-America, no obvious patterns of

257 urban area expansion/brand-new cities could be found since 1972 (see Figure 1). Thus

258 the ratio of land cover type changes (from vegetated land surface to anthropogenic 
material overlays) may be the reason.

260 Similar comparisons between city sizes and their related seasonal MODIS LST

261 tendencies in China and America (Figure 5) demonstrate that daytime cooling

262 tendency (in small cities) occurs in China, while in US-America it could only be

263 found in summer, and the daytime warming tendency, which is observed in the other

264 three seasons, is independent of city size. The nighttime warming in China

265 (US-America) accounts for $97.56 \%(66.67 \%), 97.15 \%(99.68 \%), 95.31 \%(81.82 \%)$

266 and $30.00 \%(63.01 \%)$ of the whole city size, with the increasing rates in terms of

267 averaged median are $1.13(0.60), 0.97(0.91), 1.06(0.70)$ and $-0.81(0.63){ }^{\circ} \mathrm{C} /$ decade

268 in spring, summer, autumn and winter, respectively. That is, for the whole China

269 (America), the magnitudes of the warming rates vary from season to season: spring >

270 autumn $>$ summer $>$ winter $($ summer $>$ autumn $>$ spring $>$ winter $)$. The seasonal

271 warming rate order in US-America is comparable with previous results based on one

272 of the megacities in China (Yangtze River Delta, Du et al. (2007)). 


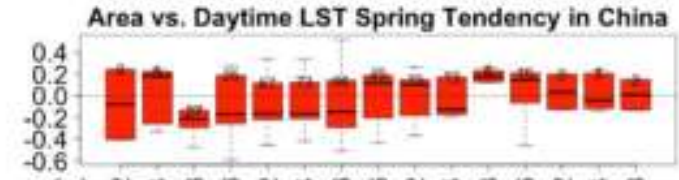

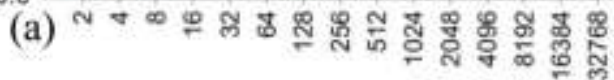

Area vs. Daytime LST Summer Tendency in China

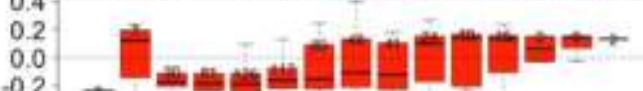

$-0.2$

$-0.4$

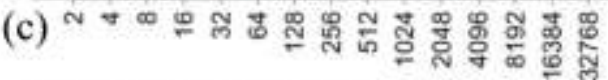

Area vs. Daytime LST Autumn Tendency in China

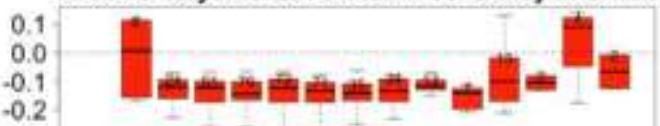

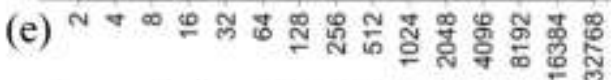

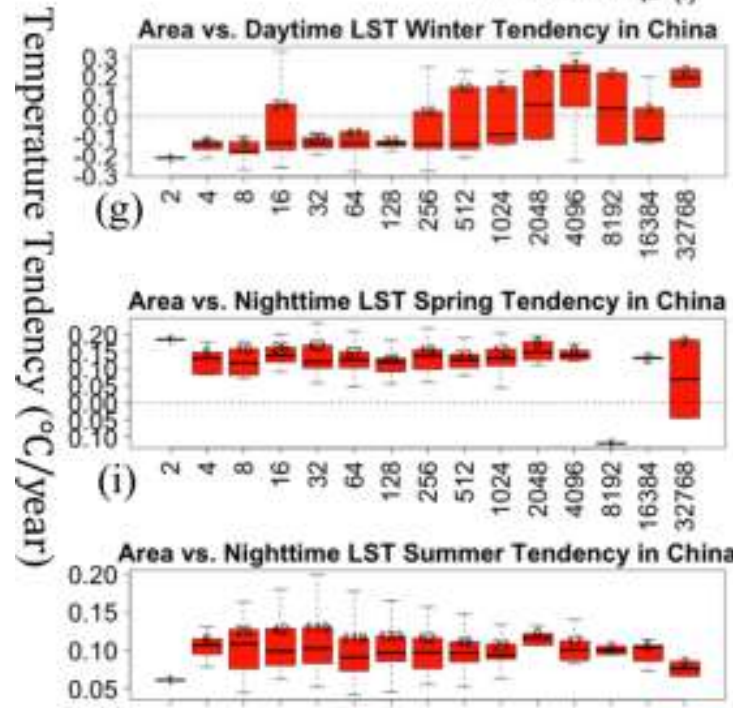

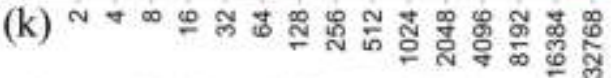

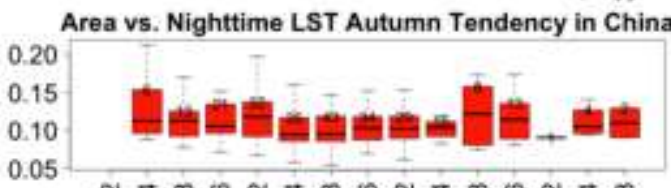

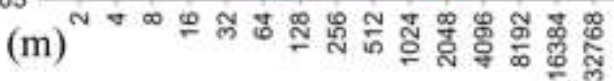

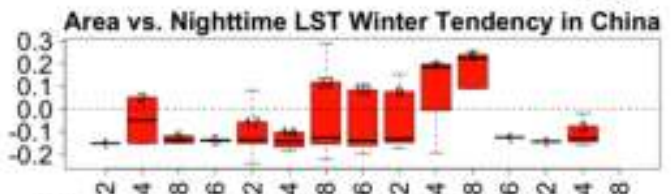

(o)

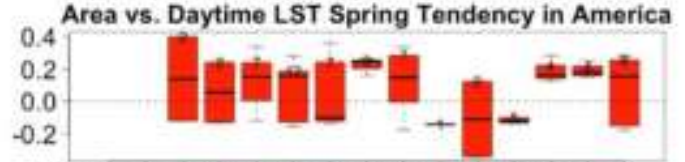

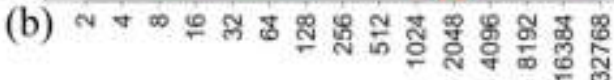

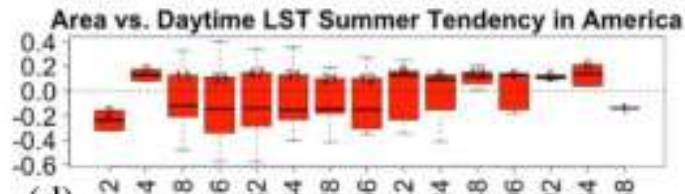

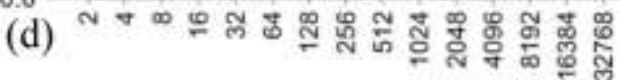

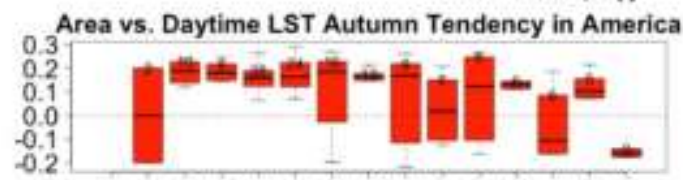

(f)
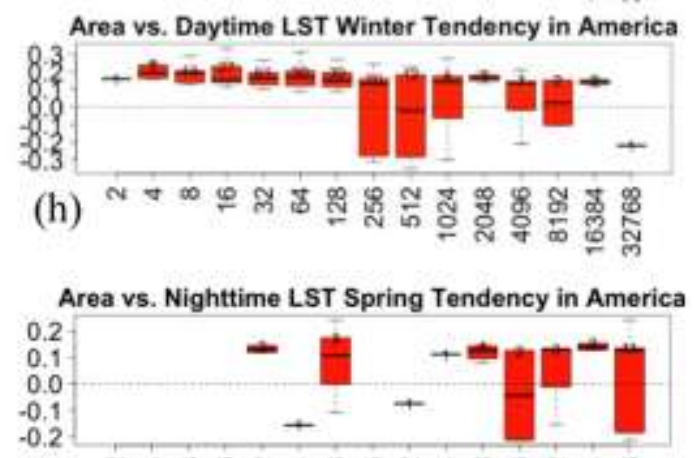

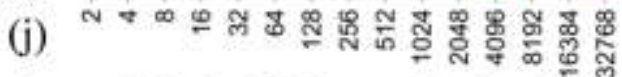

Area vs. Nighttime LST Summer Tendency in America

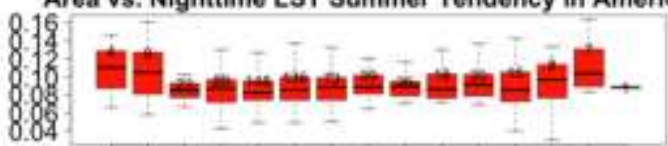

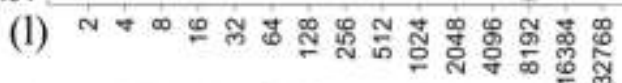

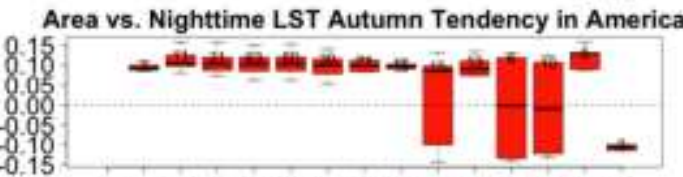

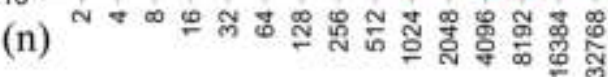

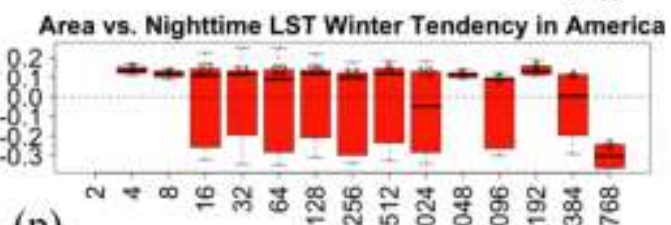

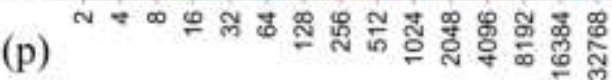

City size $\left(\mathrm{km}^{2}\right)$

Figure 5 City size dependent analyses of MODIS daytime seasonal averaged land surface temperature tendencies (2001-2012) in China and US-America: a-b) spring, c-d) summer, e-f) autumn and g-h) winter; and of MODIS nighttime tendencies: i-j) spring, k-1) summer, m-n) autumn and o-p) winter. City sizes are binned into 
278 exponentially wider bins to circumvent the situation that few numbers of cities appear 279 in large city size ranges (city size unit: $\mathrm{km}^{2}$, tendency (2001-2012) unit: ${ }^{\circ} \mathrm{C} /$ year).

\subsection{Urban Thermal Environment: Relation to City Size and Light Intensity}

281 Seasonal urban surface states in the (temperature tendency, light intensity)-diagram

282 are presented as frequency (number of cities) distribution (Figure 6), and the city size

283 information embedded in the diagram is shown in Figure 7. Both figures are used to

284 demonstrate how the urban thermal environment responds to the change of city size

285 and light intensity. The following results are noted: i) A bimodal frequency

286 distribution of city unit is aligned near light intensity 25 but separated by the zero

287 temperature change line, separating warming and cooling tendencies, which is

288 particularly pronounced for daytime temperature tendency based statistics. But for

289 nighttime temperature tendency based statistics, a uni-modal frequency distribution of

290 city unit occurs in spring, summer and autumn in China and in summer in

291 US-America, associated only with a warming tendency.

292 ii) The frequency distribution covers light intensity from $\sim 15$ to 45 , cities with similar

293 light intensity show both warming and cooling. Regions with high light intensity

294 generally correspond to fully developed urban areas with near total outdoor 
295 illumination, less brightly observations may correspond to lower built area density

296 with dimmed outdoor lights throughout or to a small number of discrete lighted areas

297 with somewhat brighter lighting (Small et al. 2011). Therefore, no linear relationship

298 shows between seasonal urban temperature tendency and light intensity, particularly

299 in daytime.

300 iii) Compared with daytime and nighttime temperature tendencies in US-America, the

301 situation, mentioned in previous research (Kalnay and Cai 2003; Ren 2015), that

302 daytime urban warming rates decline while nighttime urban warming rates increase is

303 more pronounced in China. This, to a certain extent, may be related to anthropogenic

304 air pollution within cities. Furthermore, greater concentration of aerosols in the

305 middle to lower troposphere will also affect precipitation in urban areas by modifying

306 the microphysical processes of clouds (Rosenfeld et al. 2008; Van Den Heever and

307 Cotton 2007). 

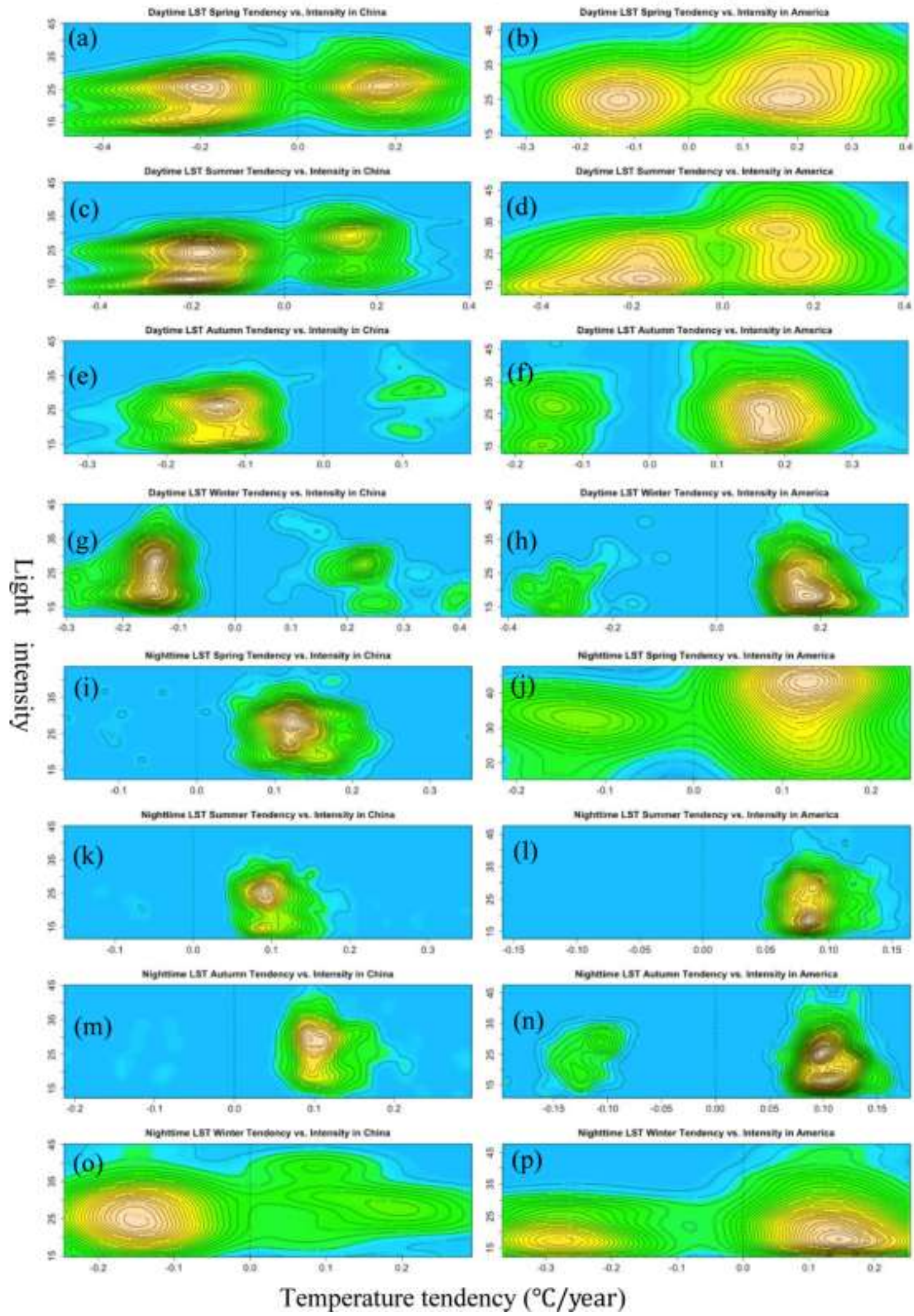

Temperature tendency $\left({ }^{\circ} \mathrm{C} /\right.$ year $)$

309 Figure 6 Density distributions of (light intensity, temperature tendency)-diagram in

310 daytime China and US-America of a-b) spring, c-d) summer, e-f) autumn and g-h)

311 winter; and in nighttime China and US-America of $\mathrm{i}-\mathrm{j}$ ) spring, $\mathrm{k}-\mathrm{l}$ ) summer, $\mathrm{m}-\mathrm{n}$ ) autumn and o-p) winter (tendency (2001-2012) unit: ${ }^{\circ} \mathrm{C} /$ year). 

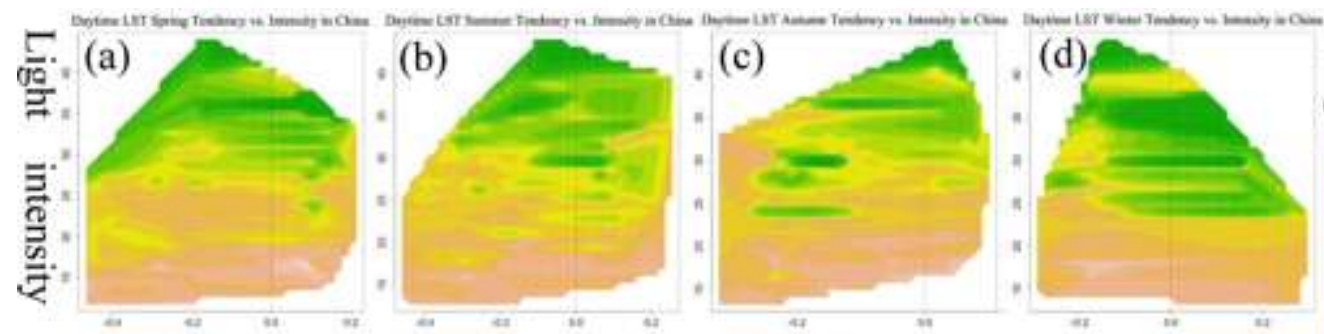

Area
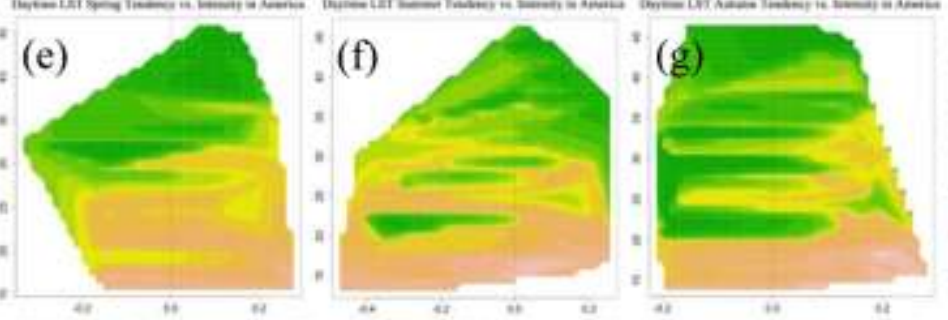

(h)

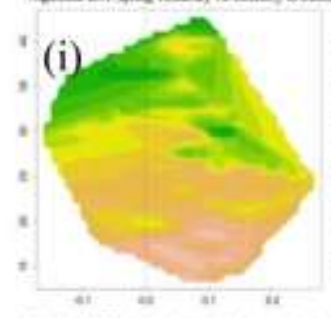

(j)

(k)

$\left(\mathrm{km}^{2}\right)$
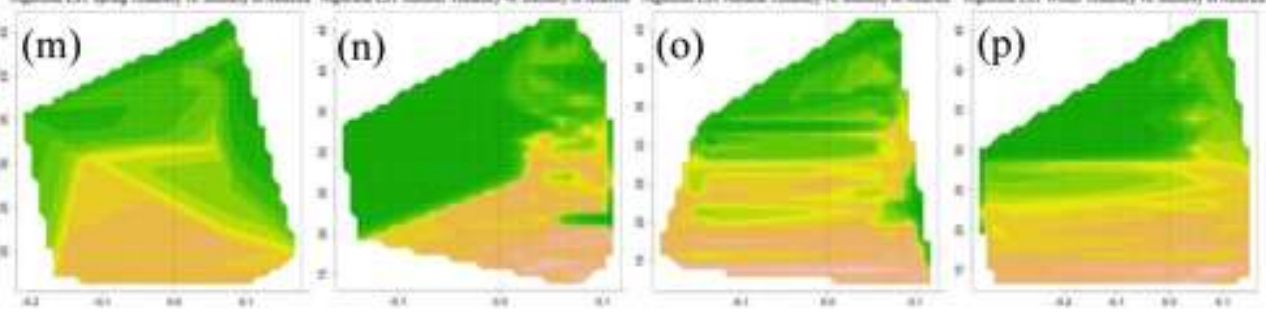

314

\section{Temperature tendency $\left({ }^{\circ} \mathrm{C} /\right.$ year $)$}

Figure 7 City size information embedded in the (light intensity, temperature

tendency)-diagram for daytime China: a) spring, b) summer, c) autumn and d) winter, versus for daytime US-America of e) spring, f) summer, g) autumn and h) winter; and for nighttime China: i) spring, j) summer, k) autumn and l) winter, versus for nighttime US-America of $\mathrm{m}$ ) spring, $\mathrm{n}$ ) summer, o) autumn and $\mathrm{p}$ ) winter (tendency (2001-2012) unit: ${ }^{\circ} \mathrm{C} /$ year).

321 Projecting the spatial information (Figure 7, smoothed frequencies) onto the 
324 statistics of the urban thermal environment; the following results are noted: i) In

325 China, the daytime spring and summer reveal bimodality of (temperature tendency,

326 light intensity)-regimes characterized by warming or cooling tendencies $(\sim \pm 0.2, \sim 25)$

327 for moderate size cities; in daytime of autumn and winter the density peak of cooling

328 tendency $(\sim-0.15, \sim 25)$ corresponds with moderate size to mega-cities. The nighttime

329 warming density peak $(\sim 0.1, \sim 25)$ in China, except winter, corresponds with moderate

330 size to mega- cities as well.

331 ii) Comparing China with US-America, daytime spring and summer bimodal regimes

332 show a similar density distribution, while there is a 'mirror' like difference of

333 temperature tendency peak (that is, cooling in China and warming in US-America)

334 appearing in daytime autumn and winter. The density peak of daytime warming

335 tendency $(\sim 0.2, \sim 25)$ in autumn and winter corresponds with megacities in

336 US-America. The nighttime warming density peak in US-America shifts from

337 megacities in spring to moderate size cities in the other three seasons. That is, most

338 cities in US-America, particularly for moderate to mega-cities, are mainly

339 characterized by urban warming both in day- and nighttime. 
iii) The area information embedded in the daytime and nighttime (temperature

341 tendency, light intensity) diagram shows slight fluctuations existing in a general

342 tendency that city size is positively related to light intensity but no linear relationship

343 lies between city size and temperature tendency. City areas of US-America embedded

344 in the nighttime (temperature tendency, light intensity)-diagram are more smoothly

345 distributed (Figures 7m-p) indicating a more uniform/balanced development of

346 megacities with respect to light intensity.

\section{3.4 Regional Application: A Downscaling Analysis}

348 China has been experiencing intensive urbanization since the 1980s, particularly in

349 the eastern part (Wu and Yang 2013). Single cities have expanded to form distinctive

350 city clusters, and the most obvious examples are the Beijing-Tianjin $\left(\sim 40^{\circ} \mathrm{N}\right)$, Pearl

351 River Delta $\left(\sim 20^{\circ} \mathrm{N}\right)$ and Yangtze River Delta $\left(\sim 30^{\circ} \mathrm{N}\right)$ city clusters (Figure 1$)$. For the

352 three city clusters (of regional scale) the urban surface states are highlighted

353 seasonally and presented as frequency (number of pixels) distribution in the

354 (temperature tendency, light intensity)-diagram (Figures 8 to 10) to estimate the effect

355 of urbanization on surface air temperature change, to detect the seasonal variation of 
urban warming in different regions, and to analyze the impact of urbanization on

357 daytime and nighttime temperatures.

358 The following results are noticed: i) Pearl River Delta and Yangtze River Delta city

359 clusters show a more uniform/balanced development with respect to light intensity

360 (the frequency peak at light intensity $\sim 55$ and $\sim 50$ ) compared with a bimodality

361 frequency distribution associated with high and low light intensity peaks separated at

362 light intensity 40 in Beijing-Tianjin city clusters. ii) In the Beijing-Tianjin city

363 cluster, the daytime summer and winter and the nighttime four seasons indicate a

364 warming tendency. In the Pearl River Delta city cluster, daytime summer and

365 nighttime spring, summer and autumn show a warming tendency and a general

366 warming tendency, except nighttime winter, is found in the Yangtze River Delta city

367 clusters. iii) The most obvious warming is in nighttime autumn Beijing-Tianjin cluster

368 with the density peak $\sim 0.4{ }^{\circ} \mathrm{C} /$ decade. In addition, an opposite temperature tendency

369 shows up for the three city clusters in nighttime winter, with a warming tendency in

370 Beijing-Tianjin cluster compared with cooling tendencies in Pearl River Delta and

371 Yangtze River Delta city clusters. iv) High light intensity regions within city clusters 
373 seasonal variability characterized by low light intensity regions.
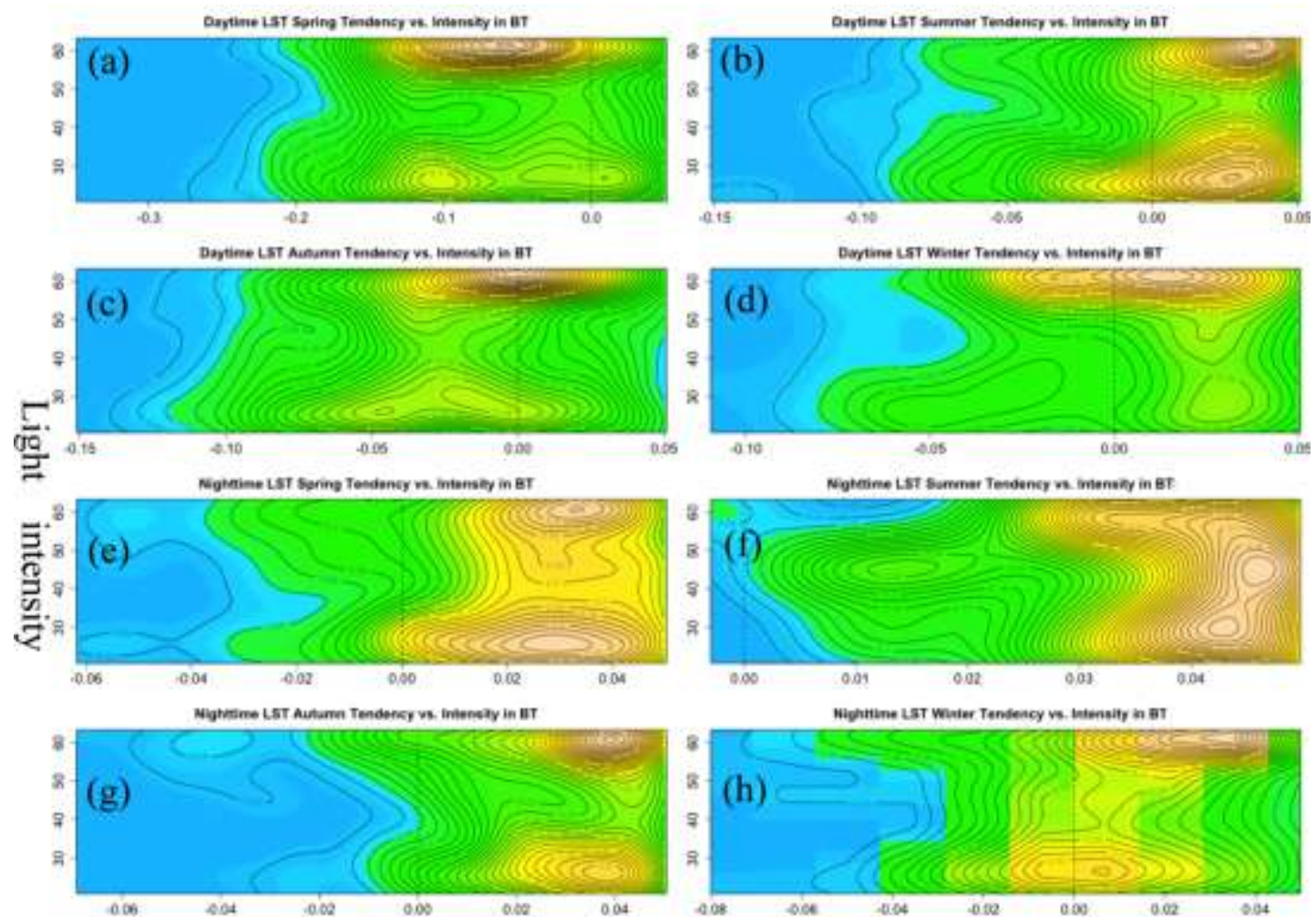

Temperature tendency $\left({ }^{\circ} \mathrm{C} /\right.$ year $)$

Figure 8 Seasonal density distribution comparison of (light intensity versus temperature tendency)-diagram in daytime Beijing-Tianjin (BT) city cluster of a) spring, b) summer, c) autumn and d) winter; and in nighttime of e) spring, f) summer, g) autumn and h) winter (tendency (2001-2012) unit: ${ }^{\circ} \mathrm{C} /$ year). 

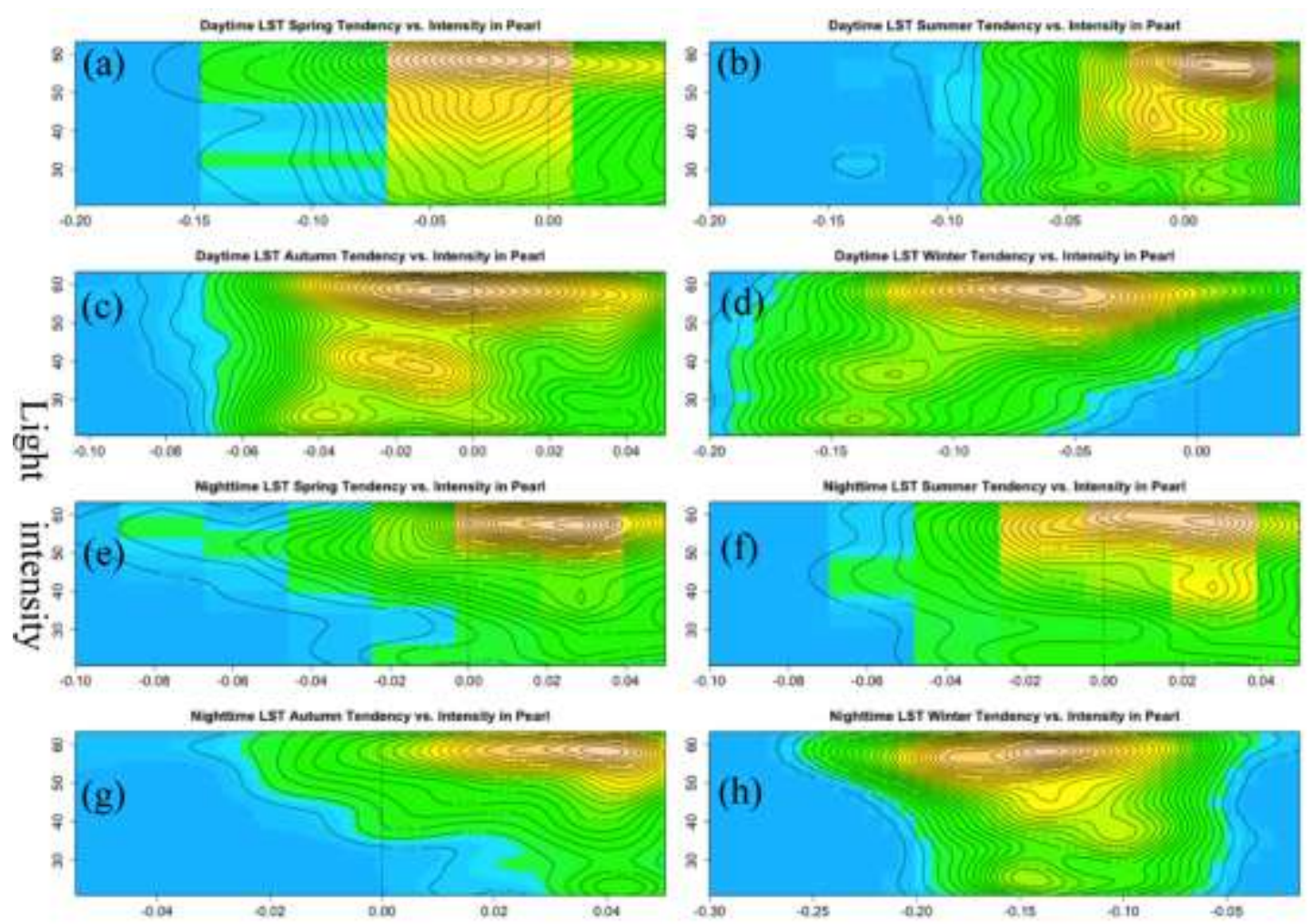

380 Figure 9 Seasonal density distribution comparison of (light intensity, temperature

381 tendency)-diagram in daytime Pearl River Delta city cluster of a) spring, b) summer, c) 

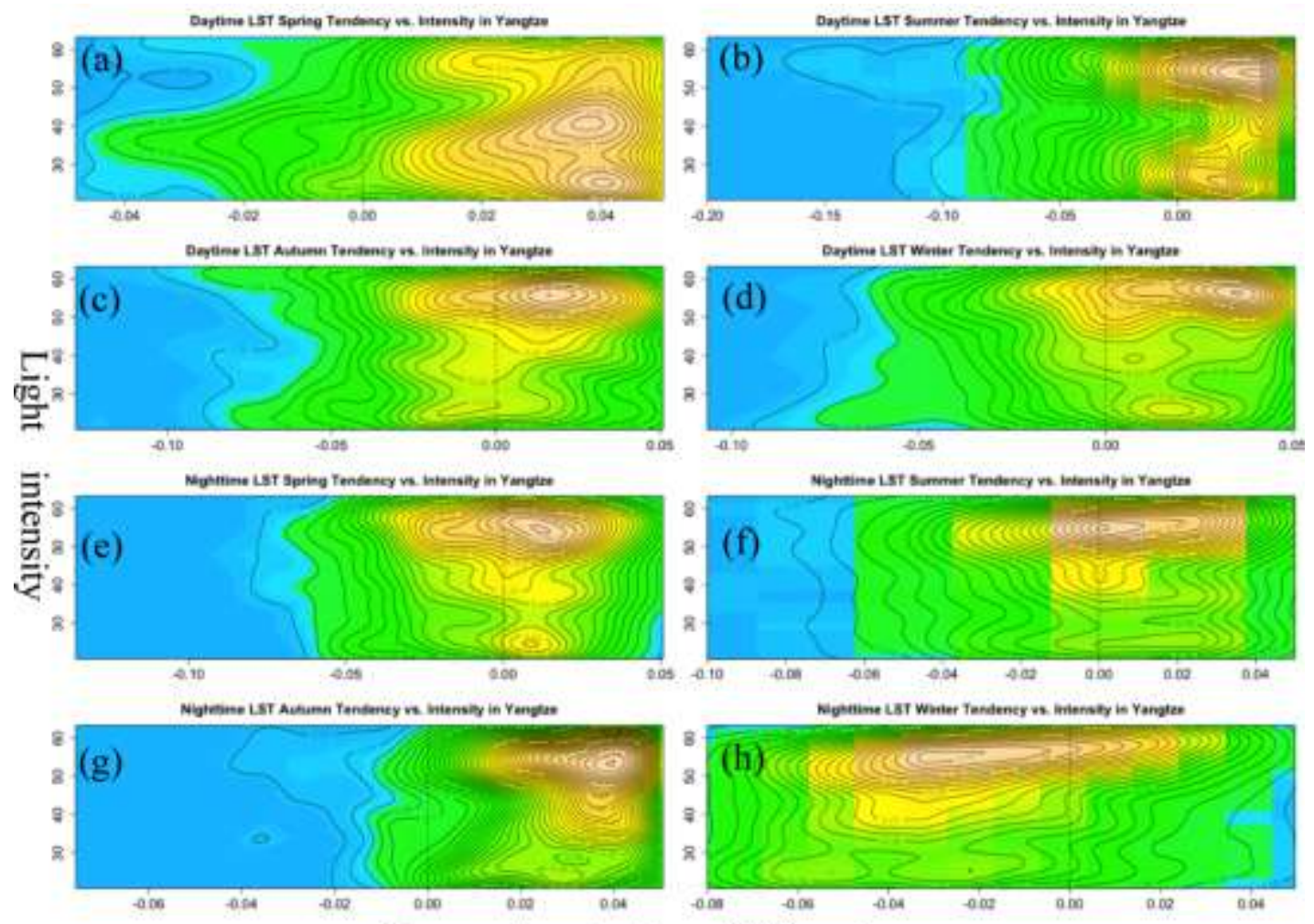

Temperature tendency $\left({ }^{\circ} \mathrm{C} /\right.$ year $)$

385 Figure 10 Seasonal density distribution comparison of (light intensity, temperature tendency)-diagram in daytime Yangtze River Delta city cluster of a) spring, b) and h) winter (tendency (2001-2012) unit: ${ }^{\circ} \mathrm{C} /$ year). 


\section{Summary and Conclusion}

390 The urbanization induced change is a major component for the formation and

391 evolution of urban climates (Grimm et al. 2008; Ren 2015; Wu and Yang 2013),

392 which affects not only the climates on local and regional scale, but also water

393 resources, air quality, human health, biodiversity and ecosystem functioning (Platt et

394 al. 1994). There are numerous studies focusing on the impact of urbanization on the

395 surface air temperature change in individual megacities (see Table 1 in $\mathrm{Wu}$ and Yang

396 (2013)). However, considerable inconsistencies exist, including differences of time

397 period, regional extent and methods of analysis. With DMSP/OLS nighttime lights

398 (2012) and MODIS LST documented for 2001-2012 and analyzed on global and

399 subcontinental scale (China and US-America), this study investigates spatial

400 heterogeneities of the urban surface environment associated with the urbanization

401 processes in terms of light intensity and city size spectrum to provide insights in

402 predicting how urban ecosystems will respond to urbanization on global scale, and for

403 developing and developed countries. City unit based (i-iii) and pixel unit based (iv)

404 main conclusions are as follows. 
405 i) Although the spatiotemporal extent and dynamics of urban surface energy fluxes in

406 China has experienced rapid urban development in the past decades, no obvious

407 distinction could be found in the relationship between city size and light

408 intensity/variability comparing statistics on global scale, and for China and

409 US-America. That is, in the city size and light intensity relationship, the general

410 tendency of light intensity clearly increases with increasing city size while small

411 countrywide-to-global fluctuations exist.

412 ii) Unlike a linear relationship, city size dependent annual or seasonal mean

413 temperature tendency could be found in daytime global and developing countrywide

414 (China) statistics. Small to moderate size cities in global and China show cooling

415 tendencies or fluctuations in daytime urban surface temperature, while except summer,

416 no remarkable city size dependent temperature tendencies are found in US-America.

417 In addition, China indicates more obvious temperature tendency fluctuations, which

418 may relate to the fact that the large and significant urbanization-induced warming has

419 contributed to changes in extreme temperature in China.

420 iii) Density statistics in the (temperature tendency, light intensity)-diagram confirm 
421 that a bimodal frequency distribution of light intensity associated with warming and

422 cooling tendencies is particularly pronounced for daytime urban surface temperature.

423 But the nighttime statistics reveals a seasonal uni-modal frequency distribution of

424 light intensity associated with a warming tendency both in China, where it is more

425 intense, and US-America. That is, cities are more likely to show urban effect in terms

426 of a temperature decrease in the daytime and an increase in the nighttime, particularly

427 for a developing country like China.

428 iv) Regional downscaling analysis on pixel scale of the Beijing-Tianjin, Pearl River

429 Delta and Yangtze River Delta city clusters indicates that Pearl River Delta and

430 Yangtze River Delta city clusters show a more uniform/balanced development

431 compared with Beijing-Tianjin city clusters, and that high light intensity regions

432 within a city cluster show a more stable warming tendency compared with seasonal

433 fluctuations in low light intensity regions.

434 Surface warming is attributed to natural climate change and anthropogenic forcing.

435 The anthropogenic forcing mainly includes the emissions of green house gases and

436 aerosols, as well as the land use and cover change (Parry et al. 2007). The 

urbanization is one of the extreme processes in the land use and land cover change

438 (Pielke 2005). Since both green house gases and urbanization tend to increase the

439 surface air temperature, it is quite difficult to estimate the relative contribution of 440 either effect to the surface warming (Kalnay and Cai 2003). Thus further research on 441 measures of multi-scale resilience and on the diagnostics of attributing the causes of 442 change is required.

443 Acknowledgements: Support by the Chinese National Science Foundation (Grant No.

444 41501375), by the Max Planck Fellow Group (DC, KF) is acknowledged. 


\section{Reference:}

Adamic, L.A. (2000). Zipf, power-laws, and pareto-a ranking tutorial. Xerox Palo Alto Research Center, Palo Alto, CA, http://ginger. hpl. hp. com/shl/papers/ranking/ranking. html

Alberti, M. (2005). The effects of urban patterns on ecosystem function. International Regional Science Review, 28, 168-192

Amaral, S., Câmara, G., Monteiro, A.M.V., Quintanilha, J.A., \& Elvidge, C.D. (2005). Estimating population and energy consumption in Brazilian Amazonia using DMSP night-time satellite data. Computers, Environment and Urban Systems, 29, 179-195

Carreiro, M.M., \& Tripler, C.E. (2005). Forest remnants along urban-rural gradients: examining their potential for global change research. Ecosystems, 8, 568-582

Doll, C.N., Muller, J.-P., \& Morley, J.G. (2006). Mapping regional economic activity from night-time light satellite imagery. Ecological Economics, 57, 75-92

Du, Y., Xie, Z.Q., Zeng, Y., Shi, Y.F., \& Wu, J.G. (2007). Impact of urban expansion on regional temperature change in the Yangtze River Delta. Journal of Geographical Sciences, 17, 387-398

Elvidge, C.D., Baugh, K.E., Kihn, E.A., Kroehl, H.W., \& Davis, E.R. (1997). Mapping city lights with nighttime data from the DMSP Operational Linescan System. Photogrammetric Engineering and Remote Sensing, 63, 727-734

Frolking, S., Milliman, T., Seto, K.C., \& Friedl, M.A. (2013). A global fingerprint of macro-scale changes in urban structure from 1999 to 2009. Environmental Research Letters, 8, 024004

Ghosh, T., L Powell, R., D Elvidge, C., E Baugh, K., C Sutton, P., \& Anderson, S. (2010). Shedding light on the global distribution of economic activity. The Open Geography Journal, 3, 147-160

Grimm, N.B., Faeth, S.H., Golubiewski, N.E., Redman, C.L., Wu, J., Bai, X., \& Briggs, J.M. (2008). Global change and the ecology of cities. Science, 319, 756-760

Henderson, J.V., Storeygard, A., \& Weil, D.N. (2012). Measuring economic growth from outer space. American Economic Review, American Economic Association, 
vol. 102(2), 994-1028.

Huang, X.M., Schneider, A., \& Friedl, M.A. (2016). Mapping sub-pixel urban expansion in China using MODIS and DMSP/OLS nighttime lights. Remote Sensing of Environment, 175, 92-108

Johnson, M.P. (2001). Environmental impacts of urban sprawl: a survey of the literature and proposed research agenda. Environment and Planning A, 33, $717-735$

Kalnay, E., \& Cai, M. (2003). Impact of urbanization and land-use change on climate. Nature, 423, 528-531

Krulwich, R. (2013). A Mysterious Patch Of Light Shows Up In The North Dakota Dark.

In http://www.npr.org/sections/krulwich/2013/01/16/169511949/a-mysterious-patch -of-light-shows-up-in-the-north-dakota-dark

Landsberg, H.E. (1981). The urban climate. Academic press

Ma, T., Zhou, C., Pei, T., Haynie, S., \& Fan, J. (2012). Quantitative estimation of urbanization dynamics using time series of DMSP/OLS nighttime light data: A comparative case study from China's cities. Remote Sensing of Environment, 124, 99-107

Mackey, C.W., Lee, X., \& Smith, R.B. (2012). Remotely sensing the cooling effects of city scale efforts to reduce urban heat island. Building and Environment, 49, $348-358$

Mertes, C.M., Schneider, A., Sulla-Menashe, D., Tatem, A., \& Tan, B. (2015). Detecting change in urban areas at continental scales with MODIS data. Remote Sensing of Environment, 158, 331-347

Montgomery, M.R. (2008). The urban transformation of the developing world. Science, 319, 761-764

Oke, T.R. (1987). Boundary layer climates. Methuen, New York

Parry, M., Canziani, O., Palutikof, J., Van der Linden, P., \& Hanson, C. (2007). Contribution of working group II to the fourth assessment report of the intergovernmental panel on climate change, 2007. Climate Change 2007: Working Group II: Impacts, Adaptation and Vulnerability 
Pataki, D., Alig, R., Fung, A., Golubiewski, N., Kennedy, C., McPherson, E., Nowak, D., Pouyat, R., \& Romero Lankao, P. (2006). Urban ecosystems and the North American carbon cycle. Global Change Biology, 12, 2092-2102

Pielke, R.A. (2005). Land use and climate change. Science, 310, 1625-1626

Platt, R.H., Rowntree, R.A., \& Muick, P.C. (1994). The Ecological City: Preserving and Restoring Urban Biodiversity. Univ of Massachusetts Press

Qu, Y.T., Meng, D., \& Chen, Z. (2013). Influence of Urbanization Process on Urban Thermal Environment in Beijing. 2013 IEEE International Geoscience and

Ren, G., \& Zhou, Y. (2014). Urbanization effect on trends of extreme temperature indices of national stations over Mainland China, 1961-2008. Journal of Climate,

Ren, G.Y. (2015). Urbanization as a major driver of urban climate change. Advances in Climate Change Research, 1, 1-6

Rosenfeld, D., Lohmann, U., Raga, G.B., O'Dowd, C.D., Kulmala, M., Fuzzi, S., Reissell, A., \& Andreae, M.O. (2008). Flood or drought: how do aerosols affect precipitation? Science, 321, 1309-1313

Schneider, A., Friedl, M.A., \& Potere, D. (2009). A new map of global urban extent from MODIS satellite data. Environmental Research Letters, 4, 044003

Schneider, A., \& Woodcock, C.E. (2008). Compact, dispersed, fragmented, extensive? A comparison of urban growth in twenty-five global cities using remotely sensed data, pattern metrics and census information. Urban Studies, 45, 659-692

Small, C., \& Elvidge, C.D. (2011). Mapping decadal change in anthropogenic night light. Procedia Environmental Sciences, 7, 353-358

Small, C., Elvidge, C.D., Balk, D., \& Montgomery, M. (2011). Spatial scaling of

533 Small, C., Pozzi, F., \& Elvidge, C.D. (2005). Spatial analysis of global urban extent 534 from DMSP-OLS night lights. Remote Sensing of Environment, 96, 277-291

535 Sutton, P., Roberts, D., Elvidge, C., \& Baugh, K. (2001). Census from Heaven: An 536 estimate of the global human population using night-time satellite imagery. International Journal of Remote Sensing, 22, 3061-3076 
538 Sutton, P.C. (2003). A scale-adjusted measure of "urban sprawl" using nighttime 539 satellite imagery. Remote Sensing of Environment, 86, 353-369

540 Sutton, P.C., \& Costanza, R. (2002). Global estimates of market and non-market

541 values derived from nighttime satellite imagery, land cover, and ecosystem $542 \quad$ service valuation. Ecological Economics, 41, 509-527

543 Taubenböck, H., Wiesner, M., Felbier, A., Marconcini, M., Esch, T., \& Dech, S. 544 (2014). New dimensions of urban landscapes: The spatio-temporal evolution 545 from a polynuclei area to a mega-region based on remote sensing data. Applied $546 \quad$ Geography, 47, 137-153

547 Thompson, R.D., \& Perry, A.H. (1997). Applied Climatology: Principles and Practice. $548 \quad$ Psychology Press

549 UN (2010). World urbanization prospects, 2009 revision. United Nations, New York

550 Utzinger, J., \& Keiser, J. (2006). Urbanization and tropical health-then and now. 551 Annals of Tropical Medicine and Parasitology, 100, 517-533

552 Van Den Heever, S.C., \& Cotton, W.R. (2007). Urban aerosol impacts on downwind 553 convective storms. Journal of Applied Meteorology and Climatology, 46, $554 \quad 828-850$

555 Wu, K., \& Yang, X. (2013). Urbanization and heterogeneous surface warming in 556 eastern China. Chinese Science Bulletin, 58, 1363-1373

557 Zhang, Q., \& Seto, K.C. (2011). Mapping urbanization dynamics at regional and 558 global scales using multi-temporal DMSP/OLS nighttime light data. Remote $559 \quad$ Sensing of Environment, 115, 2320-2329

560 Zhang, X.Y., Li, P.J., \& Cai, C. (2015). Regional Urban Extent Extraction Using 561 Multi-Sensor Data and One-Class Classification. Remote Sensing, 7, 7671-7694

562 Zhou, Y., \& Ren, G. (2012). Change in extreme temperature event frequency over 563 mainland China, 1961-2008. Climate Research, 50, 125-139 
Table 1 City size comparison for three major city clusters in China: spatially contiguous lighted areas in 2012 (with DSMP/OLS $D N \geq 12$ are classified as city boundaries).

\begin{tabular}{cccc}
\hline Pixel number $(>\mathbf{~ 1 2})$ & $\mathbf{1 9 9 2}$ & $\mathbf{2 0 0 2}$ & $\mathbf{2 0 1 2}$ \\
\hline Beijing-Tianjin Region & 13,719 & 22,327 & 44,023 \\
Pearl River Delta & 16,167 & 21,593 & 31,795 \\
Yangtze River Delta & 18,881 & 38,512 & 78,286 \\
\hline
\end{tabular}

